\title{
Letters
}

Website: bmj.com

Email: letters@bmj.com

\section{Referral of Dr Peter Mansfield to the GMC}

\section{Health authority has no power}

EDITOR-Majeed's editorial on the referral of Dr Peter Mansfield to the General Medical Council is flawed as he assumes that Worcestershire Health Authority has power in managing its responsibility for a successful public health immunisation campaign. ${ }^{1}$ It is precisely because the authority is impotent as a public statutory public body that it asked the GMC to intervene.

The continuing debate about measles, mumps, and rubella vaccine dents the confidence of many public and professional people, not least because of the assumption that there is no smoke without fire. Majeed's third reference indicates his anxiety despite his initial position statement on the safety of the vaccine. Patients and the media take heed of these different emphases.

Maintaining a high level of vaccination cover against diseases that are seen rarely or not at all poses serious difficulties. Majeed's role as an educationalist-a position of power and responsibility-could provide a forum where these difficulties are debated. The role of medical journals and the media should not be ignored in that debate. Their keenness for headlines containing bad news, however misguided or ill informed, while

\section{Advice to authors}

We prefer to receive all responses electronically, sent directly to our website. Processing your letter will be delayed unless it arrives in an electronic form.

We are now posting all direct submissions to our website within 24 hours of receipt and our intention is to post all other electronic submissions there as well. All responses will be eligible for publication in the paper journal.

Responses should be under 400 words and relate to articles published in the preceding month. They should include $\leqslant 5$ references, in the Vancouver style, including one to the BMJ article to which they relate. We welcome illustrations.

Please supply each author's current appointment and full address, and a phone or fax number or email address for the corresponding author. We ask authors to declare any competing interest. Please send a stamped addressed envelope if you would like to know whether your letter has been accepted or rejected.

Letters will be edited and may be shortened.

bmj.com

letters@bmj.com relegating good news to the middle pages or waste bins, provides a particular challenge for health education campaigns. As the chairman of Worcester City primary care group I have a responsibility for ensuring a high coverage of measles, mumps, and rubella vaccination. I am unable to identify the power I wield in this role, other than to attempt to communicate to patients, health professionals, and the media.

There is no evidence that single vaccines for mumps, measles, and rubella are safer than the combined vaccine as they have not been subject to the same level of scrutiny and no successful voluntary campaign of separate vaccinations has been conducted for these illnesses. If, however, measles, mumps, and rubella coverage falls as a result of Mansfield's and Desumo's activity, children will be more likely to contract these illnesses. Some of these children will die, as has happened in Holland and Dublin. Worcestershire Health Authority exercised its responsibility correctly by asking the GMC to intervene. Majeed offers no alternative actions for Worcestershire Health Authority, despite asserting that there are other options. His article, and the $B M J$ in choosing it as an editorial, does not do justice to the issues. I also despair about the lack of responsibility demonstrated by an educationalist who displays such a superficial understanding of this complex matter.

Richard Whitmore primary care group chairman Lyppard Grange Medical Centre, Ankeridge Green Worcester WR4 0DZ irw50@lineone.net

\section{Majeed A. Referral of Dr Peter Mansfield to the GMC. BM 2001;323:356. (18 August.)}

\section{Health authority made right decision}

EDITOR-Far from Worcestershire Health Authority being wrong in taking the decision to refer Dr Peter Mansfield to the General Medical Council I would contend that it is following through on the full implications of clinical governance. ${ }^{1}$ Each chief executive of a health authority is ultimately responsible for all clinical activity in the area. Exercising this responsibility is straightforward in the public sector, but it is different when the clinical activity takes place in the private sector. When a health authority is made aware of clinical activity at variance with best practice in the private sector, it is still duty bound to investigate and act.

When such investigations uncover shortfalls in care, as is possible, only a limited number of actions are available to the authority. These are as follows:

- Publicising its concerns and risking lengthy legal consequences even if it is correct

- Developing services locally. These need to be so clearly better that demand dissipates for private operators

- Referring the practitioner to his or her governing professional body.

Worcestershire Health Authority was left with only the third option. The government, in conjunction with the NHS, had mounted a high level public information campaign making clear the concerns over vaccination with anything other than the measles, mumps, and rubella vaccine. Local service development is not an option as patient choice is being exercised in spite of the advice on best practice.

In light of the public health concerns surrounding this particular topic Worcestershire Health Authority would have been negligent had it not referred Dr Mansfield to his governing body. All we see in this case is the dynamic of clinical governance coming against that of clinicians' freedom and patients' free will. Dr Mansfield's case is no different from any practitioner, medical or otherwise, who is intent on practice at variance with best practice advice. His or her case must be tested against these three dynamics. The GMC has as its motto "protecting patients, guiding doctors." With its ability to draw on legal, professional, and patient based advice, the GMC is ably placed to balance these dynamics and reach a sensible conclusion

Malcolm Alexander clinical director Orkney Health Board, Kirkwall, Orkney KW16 3HA malcolm_alexander2000@yahoo.co.uk

1 Majeed A. Referral of Dr Peter Mansfield to the GMC. BMJ 2001:323:356. (18 August)

\section{Doctors seem to have to march in step}

EDitor-I am not qualified to comment on vaccines but I admire Majeed's resolute and eloquent defence of the right to reasonable dissent from official views. ${ }^{1}$

Much of the evidence on which modern treatment is based is derived from studies in large, often carefully selected, populations. When such treatment is then applied to similar populations the benefits and risks are predictable. That is the science. Not every individual, however, fits comfortably into convenient algorithms. For these people, management is influenced by clinical judgment, perceptions and preferences of patients, and so on. That is the art of medicine; it goes hand 
in hand with the science, which most practising clinicians recognise.

Guidelines can be very helpful but at times are treated as rail tracks from which deviation is difficult for fear of criticism, or worse. Approaching my 30th year as a consultant, I think we are increasingly required to march in step, no matter if the direction is questionable. It is not clear why Dr Mansfield was referred to the General Medical Council. In the absence of a reasonable explanation, the suspicion might arise that, in the current "doctor bashing" atmosphere, the authorities have tried to pre-empt any risk of being criticised by pointing out someone whose "fault" was being out of step.

K D Bardhan consultant physician and gastroenterologist

Rotherham General Hospital NHS Trust,

Rotherham, South Yorkshire S60 3NA

bardhan.sec@rgh-tr.trent.nhs.uk

1 Majeed A. Referral of Dr Peter Mansfield to the GMC. BMJ 2001;323:356. (18 August.)

\section{Should decision on vaccination be best for you or us?}

EDITOR-Although I agree with Majeed that Dr Peter Mansfield's referral to the General Medical Council seems inappropriate, this may prompt more debate around the important issue of whether it is reasonable to legislate for the rights of the community over the rights of the individual as regards vaccination for measles, mumps, and rubella.

The argument seems to be that we know that combined measles, mumps, and rubella vaccine is safe and effective (anyone who takes the time to assess the extensive literature should be able to persuade themselves of this fact) and that single vaccines may reduce adherence to the full course and show no advantage. The community therefore loses out as a result of an individual's decision, by a reduction in herd immunity and an increased chance of an epidemic. The Department of Health therefore thinks that single vaccines should not be offered on the NHS, and there is now a question as to whether this is defensible medical practice.

Other individual choices (such as aspirin or warfarin in stroke prevention) are allowed as these are not seen to affect the community directly, although they might result in a notable burden for those caring for the increased numbers of people with strokes that this would create.

The Department of Health banks on the fact that more people would take up the option of receiving single vaccines if they were available than would refuse all vaccinations if the former were not available. Although this may seem sensible from a public health and community perspective, it is sometimes difficult to communicate the lack of individual choice in this matter in the consulting room. Shouldn't we, in this age of "patient centred" medicine, trust patients to make decisions for their own children? This would mean the cost of a potential epidemic with each media scare, but give parents the freedom, responsibility, and ownership of such a decision.

Alex Manning general practitioner

Burwell Surgery, Burwell, Cambridgeshire CB5 0AF alex.sam@virgin.net

1 Majeed A. Referral of Dr Peter Mansfield to the GMC. BMJ 2001:323:356. (18 August.)

\section{Referral constitutes abuse of power}

EDITOR-I agree with Majeed and most of the correspondents on bmj.com that the referral of Dr Peter Mansfield to the General Medical Council is an abuse of power.

Three years ago when our oldest child reached the age for measles, mumps, and rubella vaccination we decided against using the combined vaccine for ethical reasons (the rubella component of measles, mumps, and rubella vaccine was derived from experimentation on an aborted fetus). Several parents with similar views have subsequently contacted me. I have had to import single vaccines for mumps, measles, and rubella for these families from Europe and Japan. This is expensive and time consuming.

According to current regulations issued by the Department of Health, single vaccines are licensed for importation only if a child has already started a course or there are serious medical concerns about the safety of measles, mumps, and rubella vaccine for a particular child. This has led some parents to take their child to France or Ireland to start a course of single vaccines and then completing the course in the United Kingdom. I wrote to the Department of Health to challenge this situation, but it took the department six months to reply and my question about the provision of ethical alternatives was not answered. These are concerned, responsible parents who want to have their children vaccinated but have unnecessary obstacles put in their way because of a lack of flexibility at the Department of Health.

The state seems to be answerable to nobody, but Dr Mansfield is in trouble for seeking to address a strongly felt need and improve vaccination rates.

Gregory Gardner non-principal general practitioner Swanpool Medical Centre, Tipton DY4 OUB g.gardner@euphony.net

1 Majeed A. Referral of Dr Peter Mansfield to the GMC. BM/ 2001;323:356. (18 August.)

* *Since preparing these letters for publication the GMC has refused to take action against Dr Mansfield (24 November, p 1204).

\section{How best to organise acute hospital services?}

\section{Models of healthcare delivery need to be compared in trials}

EDITOR-Smith ponders how acute hospital services are best organised. ${ }^{1}$ Current proposals commend hospitals and networks serving populations of $500000^{2}$; Smith writes that the evidence that hospitals of such size are necessary to ensure high qual- ity care is moderate for some surgical services but unclear for medical services.

But evidence in the surgical and oncological literature shows that outcomes of malignant diseases are better when patients are looked after by specialist teams rather than generalists. Similar evidence applies to joint replacement, treatment of fractured neck of femur and urological conditions, and vascular surgery.

Medical emergencies are a large part of care in most acute general hospitals in the United Kingdom. It was to deal with these that Andy Black devised his model (described by Smith), whereby patients would be first admitted to a local small hospital that would, in effect, be an assessment arm of the big hospital.

Studies in the past 10 years across the range of medical emergencies have shown better care in terms of process and outcome for asthma, ${ }^{3}$ gastrointestinal haemorrhage, ${ }^{4}$ ischaemic heart disease, ${ }^{5}$ stroke, and rehabilitation in acutely ill elderly patients. Delay in implementing optimal management in such conditions can affect outcome.

As well as achieving better outcomes, specialist teams also achieve more precise diagnosis. In the respiratory field in our hospital, patients with chronic obstructive pulmonary disease or the hyperventilation syndrome are misdiagnosed as having asthma almost daily. If they were not transferred to the specialist team they would receive inappropriate management and unnecessary drug treatment. In the present state of health service resourcing, the appropriate range and number of specialists and specialist teams can only be provided in a reasonably large acute general hospital.

The tension between access and quality that exists in any healthcare system is aggravated when that system is seriously underresourced. Innovative suggestions such as that of Black need to be tested in trials. Such trials need to evaluate not only clinical outcomes and access but also costs and effective use of resources.

Doctors working in hospitals expect to base their practice on published evidence from basic and clinical science. We should expect the same of planners. The NHS provides a wonderful, and underused, testbed for the evaluation of different models of healthcare delivery.

Brian Harrison consultant physician

David Ralphs consultant surgeon

Norfolk and Norwich University Hospital, Norwich NR1 3SR

brian.harrison@norfolk-norwich.thenhs.com

1 Smith R. How best to organise acute hospitals services? BMJ 2001;323:245-6. (4 August)

2 Royal College of Surgeons of England. The provision of elective surgical services. London: RCS, 2000.

3 Pearson MG, Ryland I, Harrison BDW (on behalf of the BTS Standards of Care Committee). National audit of acute severe asthma in adults admitted to hospital. Qual Health Care 1995;4:24-30.

4 Masson J, Bramley PN, Herd K, McKnight GM, Park K, Brunt PW, et al. Upper gastrointestinal bleeding in an open-access dedicated unit. I $R$ Coll Phys Lond 1996;30:436-42.

5 Schreiber Tllkhatib A, Grines CL, O'Neill WW. Cardiologists versus internist management of palents with unstable angina: treatment patterns and outcomes.J 


\section{Real time teleneurology can help small hospitals}

EDITOR-It is good to see Smith highlighting the fact that there is no evidence that medical patients are managed any better at large teaching hospitals than in smaller hospitals.'

For the past three years, colleagues and I have been using real time telemedicine to provide the model proposed by Andy Black ${ }^{1}$ for neurology admissions to Tyrone County Hospital in Northern Ireland. This small rural hospital caters for about 60000 patients and is $53 \mathrm{~km}$ from the regional neurology centre in Belfast. A series of papers has shown that this practice is feasible, acceptable, and practical for patients with neurological symptoms admitted to hospital..$^{2-4}$

We have shown that most of these patients-who make up a fifth of all medical admissions ${ }^{5}$ - can be managed perfectly adequately in their local hospital with specialist advice. Of 230 consecutive patients seen by telemedicine, only seven had to be transferred to the regional neurology unit. The ease of access to specialist care is greatly welcomed by the patients, their doctors, and their local politicians.

Even though we have carried out successful research and development to show that this system is effective and cost effective, we are still having difficulty in implementing it in the mainstream of the NHS in Northern Ireland.

Victor Patterson consultant neurologist Royal Victoria Hospital, Belfast BT12 6BA vp498@utvinternet.com

1 Smith R. How best to organise acute hospitals services? BMJ 2001;323:245-6. (4 August.)

2 Craig JJ, McConville JP, Patterson VH, Wootton R. Neurological examination is possible using telemedicine. $J$ Telemed Telecare 1999;5:177-81.

3 Craig JJ, Russell C, Patterson VH, Wootton R, User satisfaction with real-time teleneurology. J Telemed Telecare 1999;5:237-42.

4 Craig J,Russell C, Wootton R, Patterson V. Interactive videoconsultation is a feasible method for neurological inpatient assessment. Eur J Neurol 2000;7:699-702.

5 Morrow JI, Patterson VH. The neurological practice of a district general hospital. J Neurol Neurosurg Psychiatry 1987;50:1397-40

\section{Kidderminster is ideal site for pilot trial}

EDITOR-Smith's editorial recognises that patients throughout England deserve a better model for acute hospital services than the one that led to the drastic downgrading of Kidderminster Hospital with the consequent loss of a parliamentary seat held by a government minister. ${ }^{1}$

It is not too late to improve acute emergency services for patients and their families in northwest Worcestershire and south Shropshire. Kidderminster is the ideal site for a pilot trial of Andy Black's proposals ${ }^{1}$; local people would welcome this. Facilities still exist, and nurses have shown their willingness to return.

But the government and the West Midlands regional office of the Department of Health have to accept, as the Royal College of Physicians and the NHS Confederation already have done, ${ }^{1}$ that the delivery of acute emergency services in hospitals must be rethought. Without urgent recon- sideration of the Worcestershire acute services plan the destruction of these facilities at Kidderminster will start soon. The opportunity to respond to local need and to provide a national trial site without the risk of promoting strife elsewhere will then be lost.

Richard T Taylor independent MP for Wyre Forest House of Commons, London SW1A 0AA rtt@rtact.freeserve.co.uk

Dr Taylor is chairman of Kidderminster Hospital Campaign.

1 Smith R. How best to organise acute hospital services? $B M$ 2001;323:245-6. (4 August)

\section{Radical thinking already exists in Kidderminster}

Editor-Smith's editorial on organising acute hospital services raises importan issues, but his example was ill chosen. Kidderminster Hospital is not closing but will remain open as an integral part of acute hospital services for Worcestershire; it will in fact fulfil a role similar to that which he put forward.

Within our reorganised acute services most medical admissions currently come to the main site at Worcester, but the doctors are developing daily urgent assessment and triage clinics at Kidderminster. These will run alongside an ambulatory care centre that will provide high technology diagnostic imaging facilities and extensive outpatient facilities and ambulatory surgery. The minor injuries unit already has telemedicine links to the main accident and emergency site, and an on-board telemetry link to the coronary care unit provides for thrombolysis in ambulances.

The local primary care trust is involved in developing the ambulatory care centre so that the patient pathway is integrated between primary and secondary care with a range of "step up" and "step down" options. General practitioners have already developed non-hospital options for preventing admission and for support on discharge, and they now have a general practice unit in the hospital.

The health authority, with the county council, has developed public transport links between the hospital sites for staff, patients, and visitors. This will have substantial public health benefits in improving and integrating public transport in a rural county.

These service models are part of an overall attempt to tackle the conflicting demands of modern medicine. As Smith says, there is no single solution for reconfiguring acute services, but the health authority has recognised the tension between the need for specialisation and that for local access. We planned our reconfiguration holistically to try to address this tension.

There is a large difference between the model proposed in 2001 and that proposed in $1999,{ }^{2}$ let alone the BMA's earlier views on "super hospitals." ${ }^{4}$ Given the time span for planning and building new hospitals, how do we achieve any logic or consistency when advice from experts shifts so rapidly?
Paradoxically for the BMA, Smith may be pointing the NHS towards greater involvement with schemes built under the private finance initiative. Faster build times (and completion on time and on budget) allied with the NHS being freed from its traditional preoccupation with "owning" buildings may give us greater flexibility to respond to changing circumstances.

Brian McCloskey director of public health

Worcestershire Health Authority, Worcester

WR4 9RW

Brian.McCloskey@wha.worcester-ha.wmids.nhs.uk

Professor McCloskey initiated the review that led to the changes at Kidderminster Hospital.

1 Smith R. How best to organise acute hospitals services? BMI 2001;323:245-6. (4 August)

2 Joint Consultants Committee. Organis

hospital services. London: BMA, 1999.

Britich Medical Association, Royl College of Physica London, Royal College of Sureons of England Provision of are Royal College of Surgeons of England. Provision London: RCS, 1998.

4 British Medical Association. Leaner and fitter. What future model of delivery for acute hospital services? London: BMA, 1997

\section{Acupuncture for treatment of chronic neck pain}

\section{Reanalysis of data suggests that effect is not a placebo effect}

EDITOR-Irnich et al reported that acupuncture was superior to massage though not to sham acupuncture for neck pain. ${ }^{1}$ This suggests that acupuncture is effective but that this is due to a placebo effect.

The statistical method used (comparing improvements in pain between groups with pairwise $t$ tests) is of questionable efficiency. Firstly, regression analysis including baseline score as a covariate has greater statistical power than comparison of change. ${ }^{23}$ Secondly, each pairwise comparison in a three group trial ignores one third of the patients; such comparisons are thus underpowered when compared with regression modelling of all data.

Analysis of change scores, such as that reported, favours the group with worse baseline pain scores (in this case, the group that had sham acupuncture) because of regression to the mean ${ }^{4}$; conversely, analysis of follow up scores alone favours the group with less baseline pain. Regression analysis gives similar results regardless of the direction of baseline imbalance.

Irnich kindly provided me with raw data for reanalysis. To compare the effects of treatment on pain score one week after treatment (the prespecified primary outcome measure) I undertook a linear regression analysis. The covariates used were baseline score; treatment group; and several diagnostic variables (somatisation, depression, history of trauma, pain localisation, pain site (neck/other), pain type (relieved by heat/not relieved by heat), concomitant symptoms, neurological findings, and diagnosis (myofascial/other)).

Treatment was coded as two dummy variables: use of any acupuncture technique 
and use of true acupuncture. Acupuncture, sham laser acupuncture, and massage were thus coded 1,$1 ; 1,0$; and 0,0 respectively. This analysis estimates the effects of acupuncture needling and placebo effects of acupuncture independently. Backwards stepwise regression was used where a $\mathrm{P}$ value of 0.05 was the criterion for keeping a variable in the model. Analyses were conduced on Stata 6 (College Station, Texas).

Depression, baseline score, and use of true acupuncture remained in the final regression model. The interpretation is that acupuncture needling is of benefit in neck pain and that this is not attributable to a placebo effect. Patients receiving true acupuncture had improvements in pain (adjusted for baseline score and presence of depression) of 11.5 points $(95 \%$ confidence interval 3.5 to 19.5 points; $\mathrm{P}=0.005)$ more than those in the massage and sham groups. When the analysis was restricted to patients who received either sham laser or true acupuncture, acupuncture led to a reduction in pain score (adjusted for baseline pain) of 9.4 points greater than sham laser ( 0.9 to 18.0 points; $\mathrm{P}=0.031)$. These results differ substantially from those reported in the original paper.

Andrew Vickers assistant attending research methodologist

Integrative Medicine Service, Biostatistics Service, Memorial Sloan Kettering Cancer Center, NY

NY 10021, USA

vickersa@mskcc.org

1 Irnich D, Behrens N, Molzen H, König A, Gleditsch J, Krauss M, et al. Randomised trial of acupuncture compared with conventional massage and "sham" laser acupuncture for treatment of chronic neck pain. $B M J$ 2001:322:1574-8. (30 June.)

2 Frison L, Pocock SJ. Repeated measures in clinical trials: analysis using mean summary statistics and its implications analysis using mean summary statistics

3 Senn S. Statistical issues in drug development. Chichester: John Wiley, 1997.

4 Bland JM, Altman DG. Regression towards the mean. BM 1994;308:1499.

\section{Authors' reply}

EDITOR-Vickers's results support our conclusion regarding the short term effects of acupuncture and provide more insight. We appreciate the statistical approach using linear regression models.

When planning the trial we had a strict focus on defining the main outcome measure and the primary analysis in order to keep the overall significance level to 0.05 for the primary hypothesis. For the comparison of all three treatments we used Dunnett's test, which controls the significance level for multiple testing. No adjustment for baseline characteristic was planned as the randomisation should ensure sufficient homogeneity between the groups. At the end of the study we followed our planned analysis procedure for a formal statistical justification of keeping the type I error below 0.05 . With this is mind, all further analyses have to be considered as secondary and supportive.

Vickers's further analysis of the data supports the study findings and especially our findings of positive effects of acupunc- ture. As secondary analysis, however, the result cannot contribute to an a posteriori formal statistical proof of the superiority of acupuncture.

Dominik Irnich research fellow

Department of Anaesthesiology, University of

Munich, 80336 Munich, Germany

Dominik.Irnich@lrz.uni-muenchen.de

Martin Krauss statistician

Biometric Centre for Therapeutic Studies, 80336 Munich

\section{Vaginal delivery after caesarean section}

Study's focus on induction $v$ spontaneous labour neglects spontaneous delivery

EDITOR-Josefson reports on a study by Lydon-Rochelle et al that found that induction of labour was associated with increased risk of uterine rupture. ${ }^{1}$ Although the research isolated prostaglandins from other forms of induction, it failed to isolate those women induced specifically with oxytocic drugs and those who were not induced but were given augmentation. This more specific stratification could entirely change the risk levels and clinical implications for particular groups.

The study found that induction of labour without prostaglandins increased the relative risk significantly (to 4.9). As this cohort presumably included women who had induction by artificial rupture of the membranes, medicated forms of induction within this "other" category could pose an even higher relative risk.

Recent studies looking at augmentation have found it also to be associated with uterine rupture..$^{2-5}$ For example, Zelop et al found that induction with oxytocin was associated with a 4.6-fold increase in uterine rupture, and augmentation with a 2.3-fold increase. ${ }^{4}$ Because it is reasonable to assume that a good portion of the "inductions without prostaglandins" in the study reported by Josefson involved oxytocics, oxytocin induction and augmentation may be implicated.

By not clarifying which mothers were given augmentation the study lacks a clear cohort of mothers who had no intervention at all. Women who have had a previous caesarean section but neither induction nor augmentation could prove to be at lower risk of rupture than any of the groups isolated in the study. Isolating women who had no medicinal or mechanical stress could show that vaginal delivery for these women has a similar level of safety as the prescribed elective repeat caesarean.

Betty-Anne Daviss chair

Statistics and Research Committee, Midwives Alliance of North America Midwifery Collective, Ottawa, Ontario, Canada K1S 2Z7

midwife@istar.ca

1 Josefson D. Vaginal delivery after caesarean section triple risk of uterine rupture. BMJ 2001;323:68. (14 July.)

2 Blanchette H, Blanchette M, McCabe J, Vincent S. Is vaginal birth after cesarean safe? Experience at a community hospital. Am J Obstet Gynecol 2001;184:1468-84.
3 Baskett TF, Kieser KE. A 10 year population-based study of uterine rupture. Obstet Gynecol 2001;97(4 suppl 1):S69.

4 Zelop CM, Shipp TD, Repke JT, Cohen A, Caughey AB, Lieberman E. Uterine rupture during induced or augmented labor in gravid women with one prior cesarean delivery. Am J Obstet Gynecol 1999;181:882-6.

5 Grubb DK, Kjos SL, Paul RH. Latent labor with an unknown uterine scar. Obstet Gynecol 1996;88:351-5.

\section{Safety of single-layer suturing in caesarean sections must be proved}

EditoR-Josefson reports that LydonRochelle et al in Washington State found a tripling of the risk of uterine rupture with trial of labour compared with repeat caesarean section. ${ }^{1}$ Similarly, about a doubling of the risk for trial of labour was reported for California in 1995 and in a recent evaluation in Switzerland.

These analyses, however, seem to be at odds with a meta-analysis of studies conducted in the United States in the 1980s comparing trial of labour with repeat caesarean section. ${ }^{2}$ This meta-analysis did not find an increased risk of uterine rupture associated with trial of labour after caesarean section in the 11 studies (6328 births) examining the issue.

We propose that the risk differential in Washington, California, and Switzerland between repeat caesarean section and trial of labour is the result of a change in clinical practice in the late 1980s, when single-layer closure of the uterine incision during caesarean section became popular. ${ }^{3}$ An evaluation in Montreal covering 1990-2000 found a five-fold increase (odds ratio 5.2, $95 \%$ confidence interval 2.1 to 12.8 ) in uterine rupture associated with single-layer versus the traditional double-layer method. ${ }^{4}$ Among the 398 women with single-layer closure the rate of rupture was $3.3 \%$, whereas among the 1251 women with double-layer closure it was $0.6 \%(\mathrm{P}<0.001)$. Single-layer suturing could have a particularly large impact on the rate of uterine rupture among those women induced or given augmentation during labour.

Introduction of the single-layer method does not seem to have been based on evidence of safety or on evidence of not increasing uterine rupture in subsequent pregnancies. A Cochrane review of singlelayer versus double-layer closure reported no studies examining relative safety in relation to uterine rupture in subsequent births. $^{5}$

The increased risk associated with trial of labour observed by Lydon-Rochelle et al may well be the result of single-layer suturing during a previous caesarean. This would suggest that single-layer suturing should be abandoned until its safety with regard to uterine rupture in subsequent trials of labour can be established.

Kenneth C Johnson consultant epidemiologist Statistics and Research Committee, Midwives Alliance of North America, Ottawa, Ontario, Canada K1S 2Z7

Ken_LCDC_Johnson@HC-SC.GC.CA

Ina May Gaskin president

Midwives Alliance of North America, 41 The Farm, Summertown, TN 38483, USA 
1 Josefson D. Vaginal delivery after caesarean section triples risk of uterine rupture. BMJ 2001;323:68. (14 July.)

2 Rosen MG, Dickinson JC, Westhoff CL. Vaginal birth after cesarean: meta-analysis of morbidity and mortality. Obstet Gynecol 1991;77:465-70.

3 Bivins HA, Gallup DG. Cesarean closure techniques: which work best? Obstetrics Gynecology Managemen 2000;12:98

4 Bujold E, Bujold C, Gauthier RJ. Uterine rupture during a trial of labor after a one- versus two-layer closure of a low transverse cesarean. Abstracts of the 2001 21st annual meeting of the Socicty for Marnal-Fetal Medicine $A m$ Obstet Gynecol 2001;184(suppl):S18.

5 Enkin MW, Wilkinson C. Single versus two laver suturing for $\mathrm{W}$, Wikinson C. Singre versus two layer suturing for closing the uterine incision at caesarean section (Cochrane review). Cochrane Library. Issue 2. Oxford:
Update Software, 2001 .

\section{Second diphtheria booster in adults raises immunity to $92 \%$}

EDITOR-After assessing the antibody response to one diphtheria booster vaccination in adults ${ }^{1}$ we conducted a second part of the trial to determine the effect of giving a second booster dose. Of the 176 volunteers whom we originally recruited, 141 cooperated (mean age 41.0 (SD 4.0) years). After a blood sample was taken at month 6 , a second booster was given. An additional blood sample was taken a month later. The methods and results of the first part of the trial have been described. ${ }^{1}$

Six months after being given the first booster 27 of the subjects had diphtheria antitoxin titres of $<0.01 \mathrm{IU} / \mathrm{ml}$ (class 1), one had protection of limited duration (titres between $\geqslant 0.01 \mathrm{IU} / \mathrm{ml}$ and $<0.1 \mathrm{IU} / \mathrm{ml}$; class 2$)$, and 113 had protective titres ( $\geqslant 0.1$ $\mathrm{IU} / \mathrm{ml}$; class 3). After being given the second booster 130 of the subjects obtained protection against diphtheria (class 3). Six subjects remained susceptible, and five obtained protection of limited duration (table).

The proportion of subjects not fully protected fell from $19 \%$ after the first booster to $8 \%$ after the second (table). Nicolay et al found figures of $5 \%$ and $3 \%$, respectively, ${ }^{2}$ and in the study of Hasselhorn et al $6 \%$ of the subjects did not obtain protection after one booster vaccination. ${ }^{3}$ Björkholm et al studied various doses of diphtheria toxoid and found that $29 \%$ to $14 \%$ of the subjects were not fully protected after one booster dose. ${ }^{4}$

When these results are borne in mind the feeling of security that one booster vaccination can give is misleading. For a substantial number of people travelling to central and eastern European countries, the Commonwealth of Independent States, and other high risk countries for diphtheria, the World Health Organisation's recommendation of one booster dose might be insufficient.
As no booster vaccinations are given after the age of 15 in Belgium and an important factor influencing immunity is the time since the last vaccination, ${ }^{5}$ giving booster vaccinations for diphtheria as is done for tetanus (and possibly giving them together) should be considered. Also, because antibody response is related to dose, the dose might need further investigation.

Non-response and missed vaccinations have to be taken into consideration in public health guidelines; the benefit of a second booster dose or regular administration of diphtheria booster vaccination (for example, every 10 years) therefore has to be considered.

Akke Vellinga epidemiologist

Pierre Van Damme researcher

Els Joosens assistant

Marie van der Wielen assistan

Centre for the Evaluation of Vaccination,

Department of Epidemiology and Community

Medicine, University of Antwerp, 2610 Antwerp,

Belgium

akkevel@uia.ua.ac.be

Herman Goossens professor

Laboratory of Microbiology, University of Antwerp

1 Vellinga A, Van Damme P, Joosens E, Goossens H Response to diphtheria booster vaccination in health adults: vaccine trial. $B M J$ 2000;320:217.

2 Nicolay U, Girgsdies OE, Banzhoff A, Hundt E, Jilg W. Diphtheria booster vaccination: one or two injections? Vaccine 1999;17:2223-8.

3 Hasselhorn HM, Hofmann F, Tiller FW. Boostering antitoxin diphtheria immunity in adults. Infection

4 Björkholm B, Granström M, Hagberg L. Diphtheri 4 Björkholm B, Granström M, Hagberg L. Diphtheria Vaccine 1996:14:1633-6.

5 Hasselhorn HM, Nubling M, Tiller FW, Hofmann F Factors influencing immunity against diphtheria in adults Vaccine 1998;16:70-5

\section{Risk of macular degeneration with statin use should be interpreted with caution}

EDITOR-Hall et al in their study suggest a remarkable protective effect of cholesterol lowering statins on age related macular degeneration. ${ }^{1}$ Defined as the end stage of age related maculopathy according to an international classification and grading system, ${ }^{2}$ age related macular degeneration is a common, blinding disease in elderly people, and treatment options are limited. The economic potential of new drugs for this disease would be huge, and, if confirmed by other studies, the finding of Hall et alwould have far reaching effects on promoting and prescribing statins. It is therefore important to clarify this association before we accept the outcome. Several issues need to be discussed.
This cross sectional cohort study of 379 subjects included $27(7 \%)$ people exposed to statins. The outcome, defined as both early and late age related maculopathy, was found in $20 \%$ of the cohort. Although a simplified grading method was used, this prevalence in those aged 66-75 years is compatible with other population based cohort studies. ${ }^{3}$ The expected number of subjects exposed and affected is therefore five, compared with the observed single subject. Although this is a significant correlation, we think that these small numbers warrant caution in the interpretation of the data.

The strong association between coronary artery disease and age related maculopathy that Hall et al found is not in accordance with previous studies. All population based cohort studies showed no association or a weak one between a history of cardiovascular disease and age related maculopathy. ${ }^{4}$

Also, the presumed positive association with cholesterol is not supported by the literature. Most studies found no association between cholesterol concentration and age related maculopathy or macular degeneration.

Hall et al do not report the number of drugs that were selected and tested in the study. The number of different drugs used in the population is large, and the association with one of them may have been found by chance alone. Also, Hall et al do not specify whether the results include both current and previous use. Because of the cross sectional design, the small numbers and the resulting wide confidence interval, we think that the results should be interpreted with caution. Confirmation by larger, standardised, prospective studies is needed. These studies are under way.

Redmer van Leeuwen PhD student, department of epidemiology and biostatistics

Johannes R Vingerling ophthalmologist, department of ophthalmology

Paulus T V M de Jong professor, department of epidemiology and biostatistics

Erasmus Medical Centre, NL-3000 DR Rotterdam, Netherlands

1 Hall HF, Gale CR, Syddall H, Phillips DIW, Martyn CN. Risk of macular degeneration in users of statins: cross sectional study. BMJ 2001;323:375-6. (18 August.)

2 The International ARM Epidemiological study group. An international classification and grading system for age-related maculopathy and age-related macular degeneration. Surv Ophthalmol 1995;39:367-74.

3 Vingerling JR, Dielemans I, Hofman A, Grobbee DE, Hijmering M, Kramer CFT, et al. Prevalence of age-related maculopathy in the Rotterdam Study Ophthaluolog 1995;102:205-10. 4 Klein R. Epidemiology. In: Berger JW, Fine SL, Maguire
MG, eds. Age-related macular degeneration. 1st ed. St Louis: MG, eds. Age-related

\section{Some children may not have had meningococcal $\mathrm{C}$ vaccine}

EDITOR-The immunisation programme with the new meningococcal $\mathrm{C}$ conjugate vaccine was introduced in England in November 1999. The vaccine was offered to everyone under the age of 18 with 
remarkable success, as shown by its impact on the disease. ${ }^{12}$

Guidance documents received from the Department of Health suggested that all children aged under 5 on 1 September 1999 should be offered immunisation by their general practitioners, while those aged 5 and over were to be immunised at school. In Gloucestershire we received numerous telephone inquiries from school nurses and general practitioners about clarity on who was responsible for immunising children aged over 5 who were in the reception year at school.

A recent confirmed case of group C disease in a 6 year old who was thought to have had the vaccine but was later found not to have received it raised our suspicion that a number of children may potentially have missed receiving the vaccine. Children in this category were those born between 1 September 1994 and 1 August 1995.

Data obtained from our child health surveillance system showed that of a total of 6890 children, only $4479(65 \%)$ had received their meningococcal $\mathrm{C}$ vaccine. We have identified all the children and written to their general practitioners, requesting them to check their records and update our database on the immunisation status of children who seem not to have received the vaccine. This letter would also serve as a prompt for general practitioners to remind parents of the need for the immunisation.

Our experience suggests the potential for some individuals to miss out on an important intervention as a result of government advice being misinterpreted.

Oluwatoyin Ejidokun consultant in communicable disease control

Brain O'Neill public health nurse

Gloucestershire Health Authority, Gloucester

GL1 2EL

ejidokun-t@yahoo.com

Margaret Keating child health and community nursing systems manager

East Gloucestershire NHS Trust, Cheltenham GL50 3EW

Carole Bodkin child health and records development manager

Severn NHS Trust, Gloucester GL1 1LY

1 Department of Health. Biggest vaccination drive for 40 years mashes meningitis $C$ disease. London: DoH, 2001. (Pres elease 2001/0007, 3 Jan 2001.) http://tap.ccta.gov.u doh/intpress.nsf/page/2001-0007; accessed 16 Nov)

2 Ramsay M, Andrews N, Kaczmarski E, Miller E. Efficacy of meningococcal serogroup $\mathrm{C}$ conjugate vaccine in teenagers and toddlers in England. Lancet 2001;357:195-6.

\section{Journals should see original protocols for clinical trials}

EDITOR-Gottlieb reports the criticism of the editorial in JAMA mentioning celecoxib, an arthritis drug, ${ }^{2}$ but surely more censure should be reserved for the journal that published the article and its reviewers. It is their responsibility to ensure that published articles reflect the truth.

It was widely known that the celecoxib long term arthritis safety study (the CLASS study) lasted for a median of nine (maxi- mum 13) months, as the data had been extensively presented at meetings for six months before the $J A M A$ publication. It was therefore surprising that JAMA chose to publish partial censored data from a completed trial. When I tried to begin some correspondence about this in JAMA the journal's response was that there was not sufficient interest.

Journals could protect themselves against such problems if they insisted that the original protocol was submitted with any publication describing a clinical trial. This simple expedient would protect against publication of partial data or the retrospective identification of end points that were not prospectively stated; its adoption is long overdue.

C J Hawkey professor of gastroenterology School of Medical and Surgical Sciences, Division of Gastroenterology, University Hospital, Nottingham NG7 2UH

cj.hawkey@nottingham.ac.uk

1 Gottlieb S. Researchers deny any attempt to mislead the public over JAMA article on arthritis drug. $B M J$ 2001;323:301.(11 August.)

2 Lichtenstein DR, Wolfe MM. COX-2-selective NSAIDs: new and improved? JAMA 2000;284:1297-9.

\section{Doctors seem not to be punished for dishonesty in} their cv

EDITOR-Minerva reports that one in three men and one in five women lied in their curriculum vitae. ${ }^{1}$ Anybody who has sat on an appointments committee will be aware that candidates often exaggerate. Part of this is self deception, but genuine dishonesty occurs too. One doctor claimed on his curriculum vitae to be the author of publications by another doctor who had the same surname and the same initial of his first name.

A candidate for the post of senior lecturer in a medical specialty falsely claimed to have an MD degree. The appointment would have been difficult to justify if he did not have a higher research degree. The institution later discovered the truth but did not sack him. Allegedly, managers found that other senior doctors in the institution had also claimed qualifications that they had not been awarded. The hospital sent a memo to consultants advising them not to do this.

I informed the General Medical Council, which notified me of the outcome more than two years later. Much of the delay was due to the failure of the institution to cooperate with the council's investigation. The council noted that the doctor maintained that his reference to qualifications that he did not hold was a clerical error. He claimed that he did not read the curriculum vitae typed for him by another. Would any sensible person believe that?

The council noted that the matter had been dealt with by the hospital, although the only sanction was a reprimand from the dean of the institution. An officer of the council also advised: "Notwithstanding the fact that the members (who screened the case) have decided not to progress this case by referring it to the preliminary proceedings committee, they wish me to relay their extreme concern over the matters that have been laid before them."

I understand from an officer of the GMC that a reprimand of this sort is the usual sanction from the council for claiming false qualifications. When I pointed out that the use of the word "usual" implied that this type of dishonesty by doctors is common I was told that it is.

If the potential gains from dishonesty are high and there is no deterrent punishment from employers or the GMC if one is caught is it any wonder that some doctors will lie on their curricula vitae?

Peter Wilmshurst consultant cardiologist Royal Shrewsbury Hospital, Shrewsbury SY3 8XQ peter.wilmshurst@mail.rsh-tr.wmids.nhs.uk

1 Minerva. BMJ 2001;323:408. (18 August.)

\section{Membership of GMC seems to confer extra-long life}

EDITOR-I recently received a letter from the registration directorate of the General Medical Council saying, "Our records show that you are not liable to pay the annual retention fee for the forthcoming year" and "if at any time you wish to remove your name from the register please telephone us." As I was granted exemption from such a fee some years ago (I qualified in 1947) and I could see no obvious reason why I should ask for my name to be removed from the register I queried the reason for this letter.

The reply came almost by return of post, stating, "Since changing computer systems in May this year some of the information migrated incorrectly. We currently have your date of birth as $01 / 01 / 1700 \ldots$. These migration errors generated letters confirming exemption from the annual retention fee."

I wonder if I qualify for inclusion in the Guinness Book of Records as the oldest doctor to receive such notification from the GMC. Maybe there's someone out there whose date of birth has "migrated" even further back in time, in which case I will stand down. (My real date of birth is 23/06/1923.)

David B Goss retired general practitioner 24 Barleycroft Road, Welwyn Garden City, Hertfordshire AL8 6JU

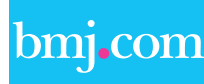

\section{Rapid responses}

Correspondence submitted electronically is available on our website 